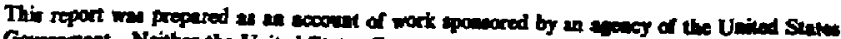

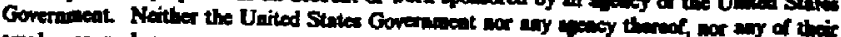

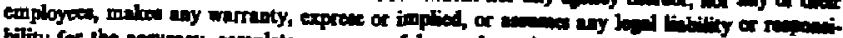

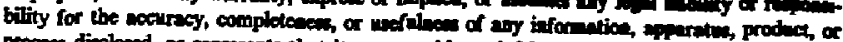

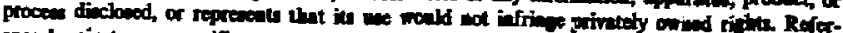

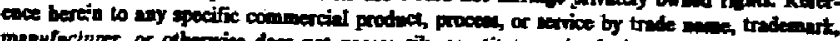

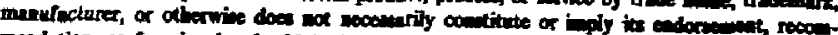

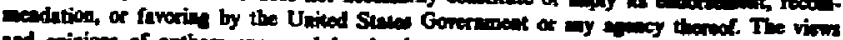

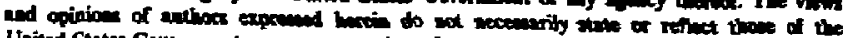
Unitod Stuted Gowtrment or any averey thened.

\title{
Fabrication of Separator Demonstration Facility Process Vessel
}

\section{Milestone Report 4406 January 15,1985}

Prepared by:

E. D. Ouret

E.F. Oberst

Reviewed by:

$\therefore=0$

J.Z. Hólz, Laser lsotope Separation

\footnotetext{
Associate Program Leader
}

UCID--20322

DE85 00731.0

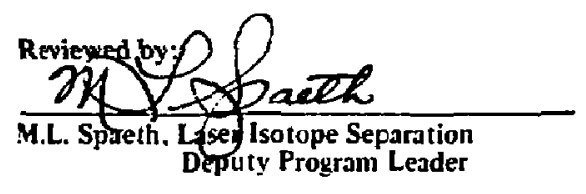

Approved by:

Lime of Ktariz

J.I. Devis. Laser Isotope Separation Program Leader

\section{LAWRENCE IIVERMORE NATIONAL LABORATORY University of California - Livermore, California $\cdot \mathbf{9 4 5 5 0}$}




\author{
Fabrication of \\ Separator Demonstration Facility \\ Process Vessel
}

\title{
1. INTRODUCTION
}

The process vessel system is the central element in the soparator Development Facility (SDF). It houses the two major process components, i.e., the laser-beam folding optics and the separator pods. This major subsystem is the critical-path procurement for the SOF project.

\section{PROCESS-VESSFL CHAMBERS}

The conceptual design for the vessel was begun in June 1383. The SDF process vessel system (Fig. 1) contains 5 chambers: a 3-sectich process chamber in the center (Fig. 2); 2 gas-scattering chambers, one on each end of the process chamber (Fig. 3); and 2 optics chambers, one at each end of the vessel (Fig. 4).

The vessel is approximately $97 \mathrm{ft}(29.6 \mathrm{~m})$ long, $16 \mathrm{ft}$ (4.9 m) iri diam, and will weigh $735,000 \mathrm{lb}(333,400 \mathrm{~kg})$ when it is fully loaded. The vessel houses several important process functions of the laser isotope separation process in addition to simply accomodating the process equipment. For example, the high-capacity vacuum system is attached to the vessel in locations designed to favorably direct the flow of gases within the vessel. The stabilization of the optics arrays is accomplished by mounting the vessel on rubber vibration isolators and straddling the optics foundation that runs the full length of the chamber. By mounting the arrays on the foundation ar.J separating them from the vessel with flexible bellaws, disturbances from such thirigs as cooling-water flaw in the pods will not disturo the critical laser light alignment. Fuur 18-ft (5.5-m)-diam Helmholtz coils located outside the process chamber deflect the electron bean througit $270^{\circ}$ from the guns munted under the crutible to the melt within the crucible. Additional. functions of each chamier of the vessel are described below. 


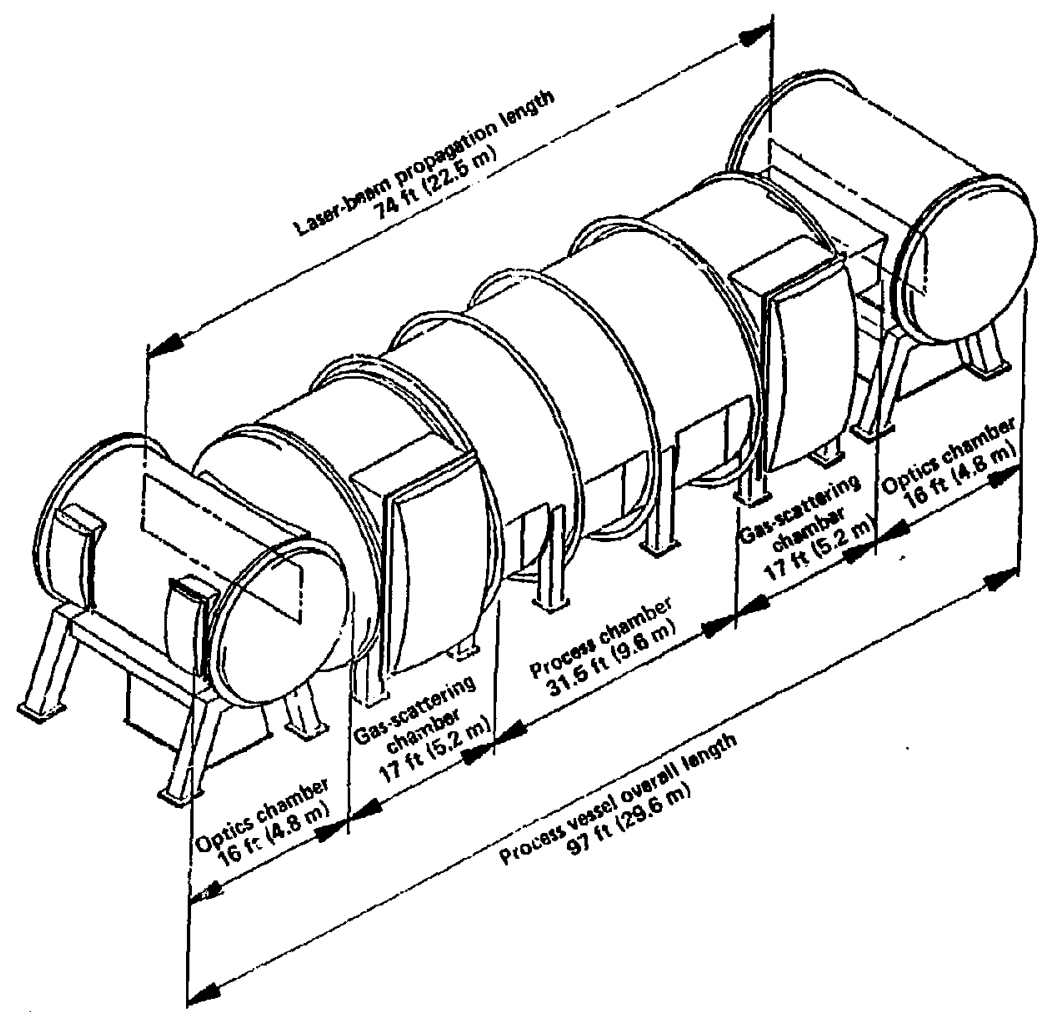

Fin. 1. Geometry of the process vessel. 

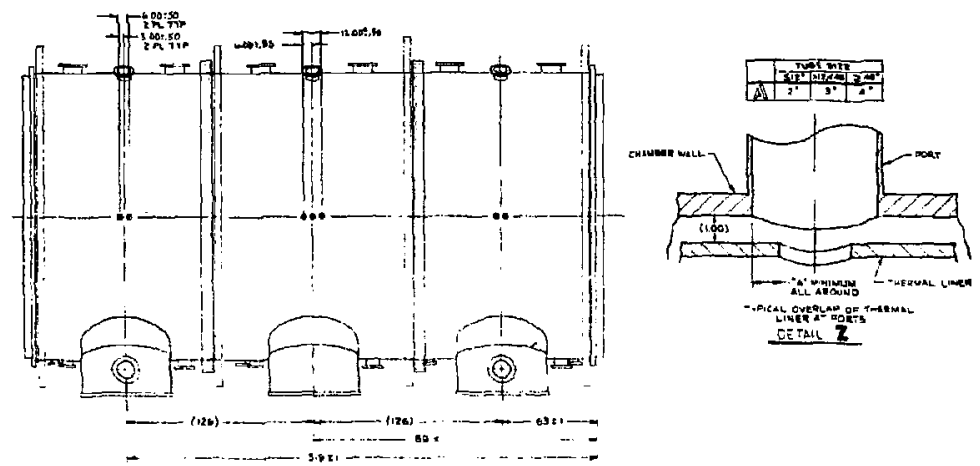

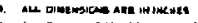

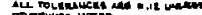

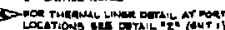

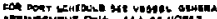

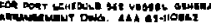

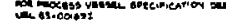

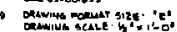

$\boldsymbol{w}$
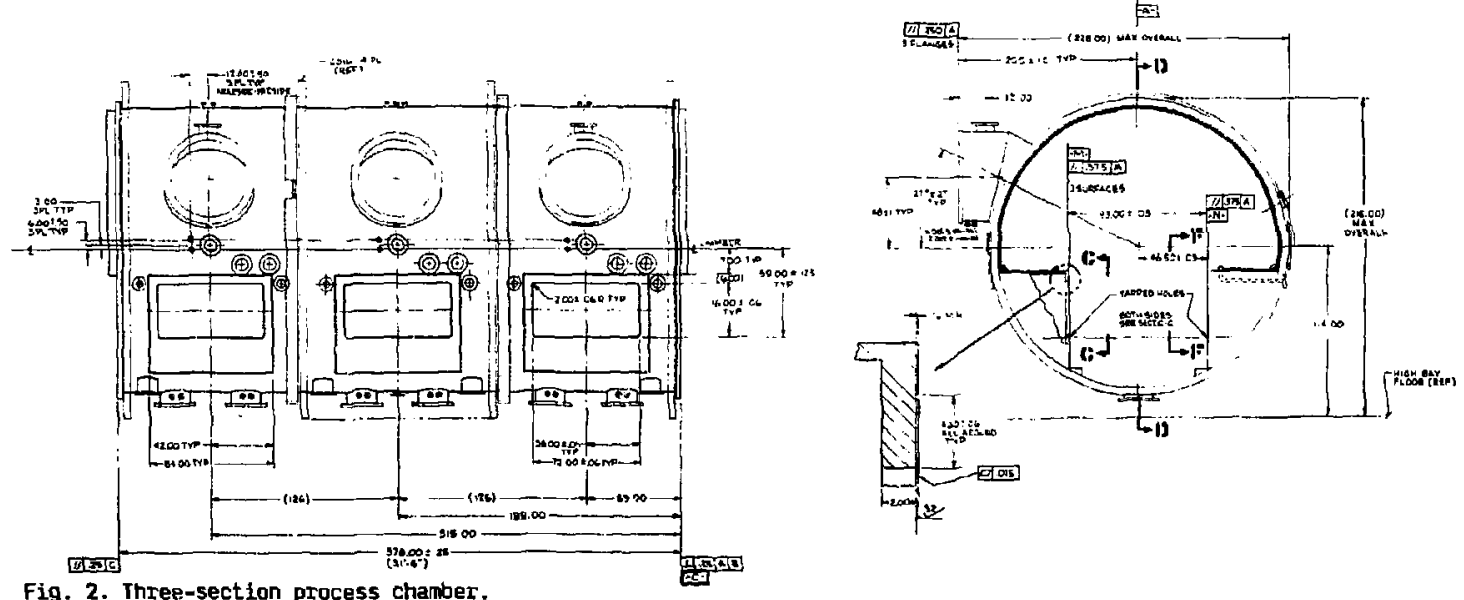

Fig. 2. Three-section process chamber. 

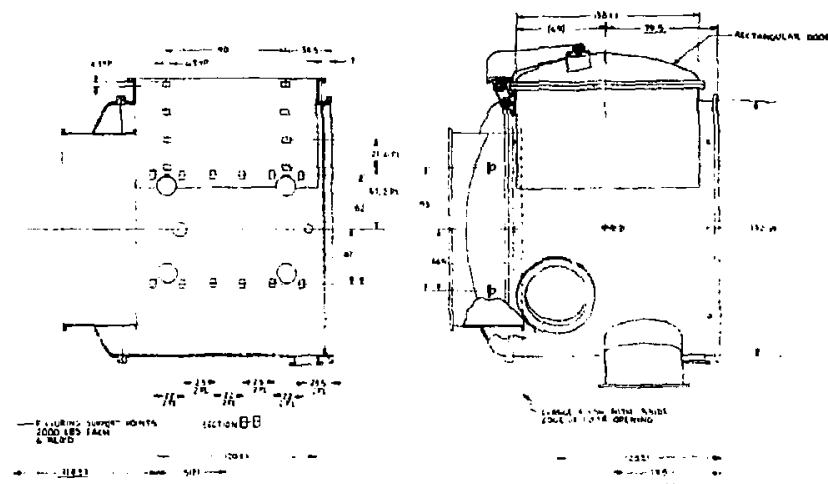

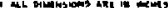

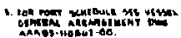

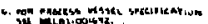

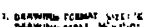
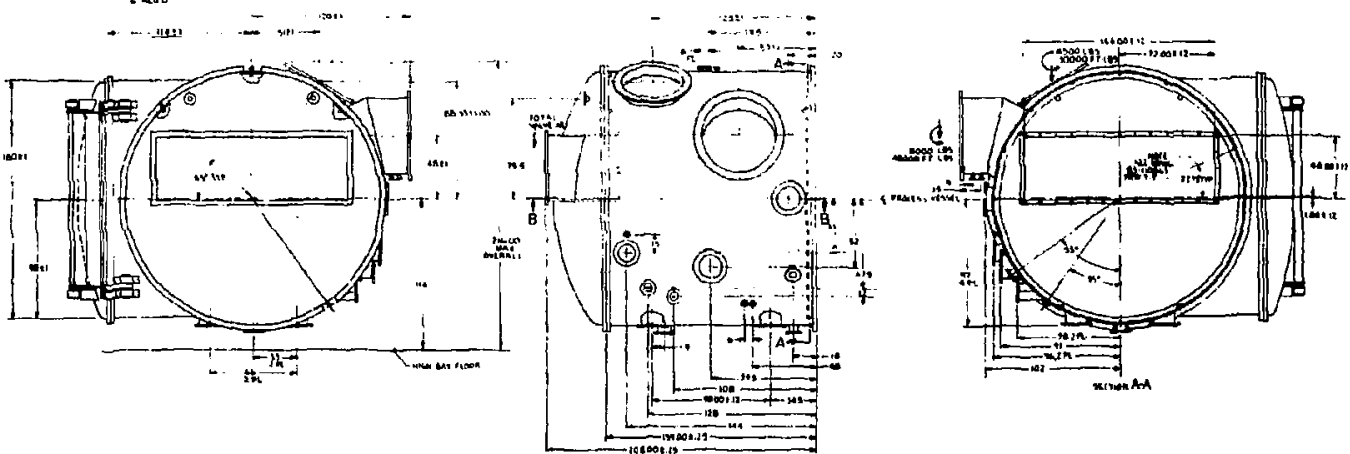

Fig. 3. Gas-scattering chamber. 


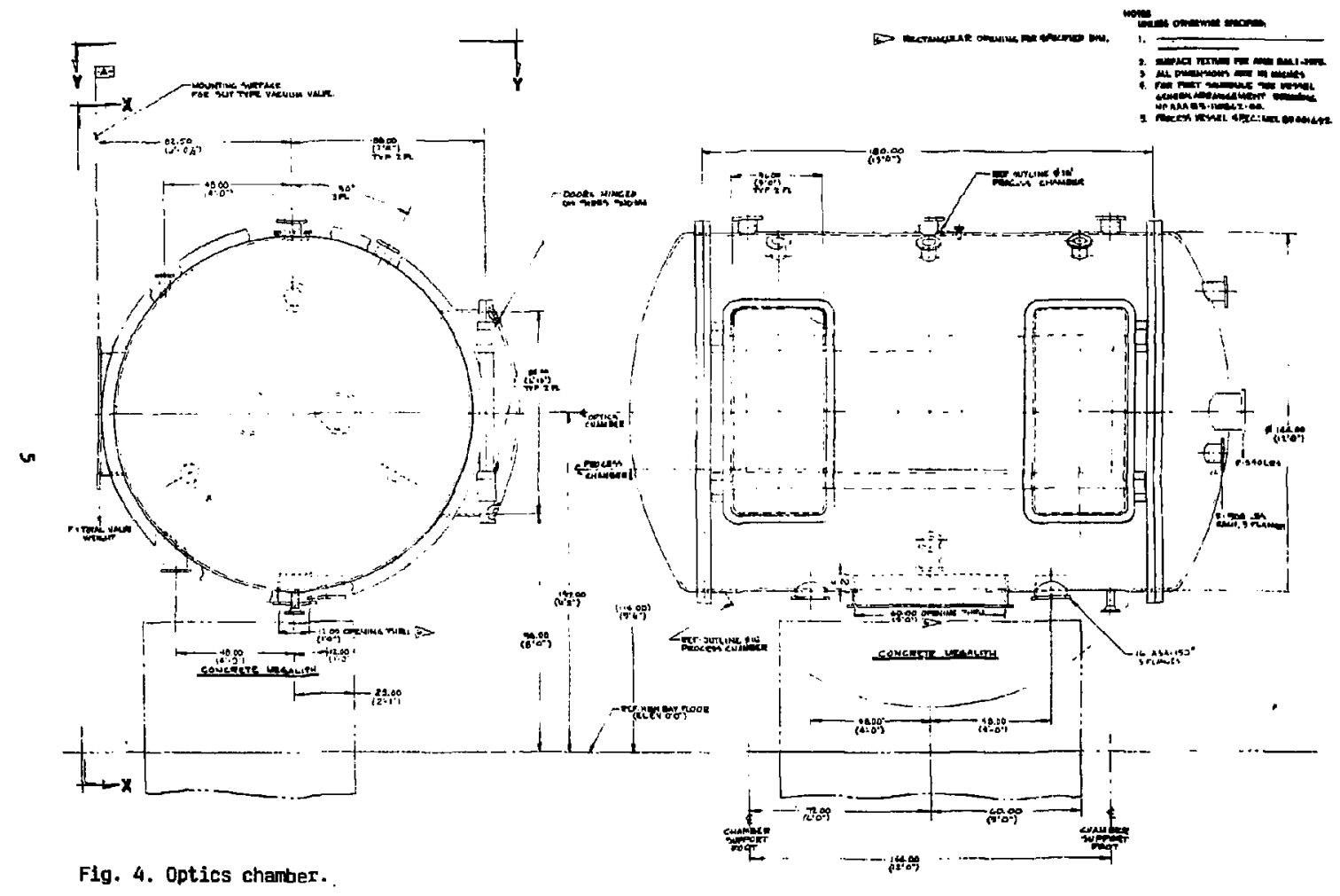




\section{THREE-SECTION PRÜCESS CHAMBER}

The process chamber (Fig. 5) will accommodate up to three process pods and their associated guns, vaporizers, separators, and utility feedthroughs. The pods are mounted on tracks to facilitate their insertion and removal from the vessel. The doors in each gas-scattering chamber and a transporter outside the vessel enaile the operators to easily handle the $24,000-1 b(10,900-k g)$ pods. The utillity panels $\{72 \times 36$ in. (183 $\times$ $91.5 \mathrm{~cm})]$ on the sides of the pods becime part of the vacuum boundary when the pods are located in the process chanber. A seal is provided by large rectangular bellows that mate the vessel port to the pod flange. This chamber also includes thermal liners to protect the vessel wall from excess process heat.

\section{GAS-SCATTERING CHAMBERS}

Protection of the optics is provided by the gas-scattering chambers. This system basically prevents the deposition of stray vapor on the optics arrays by creating a counterflow of inert gas from the optics chamber to the prucess chanber. The chambers are also equipped with $13 \times 11.5-\mathrm{ft}$. $(3.9 \times 3.5-\pi)$ doors to provide access for pod installation and removal.

\section{OPTICS CHAMEERS}

The laser optics arrays are housed in the two 12-ft (3.6-m)-diam chambers on the ends of the vessel. The necessary cleanliness requirements are maintained by two $12 \times 4-\mathrm{ft}(3.6 \times 1.2-m)$ slit-type vacuum valves located between the optics and gas-scattering chambers. The valves will be closed except when the laser optics-protection system is functioning.

\section{FABRICATION CONTRACT}

A fixed-price performance specification for the system was issued on September 26, 1983. The specification was based on the ASME pressure-vessel code and standard commercial fabrication techniques. Bids were recelved on November 16, 1983 from six firms. Following an LUNL 


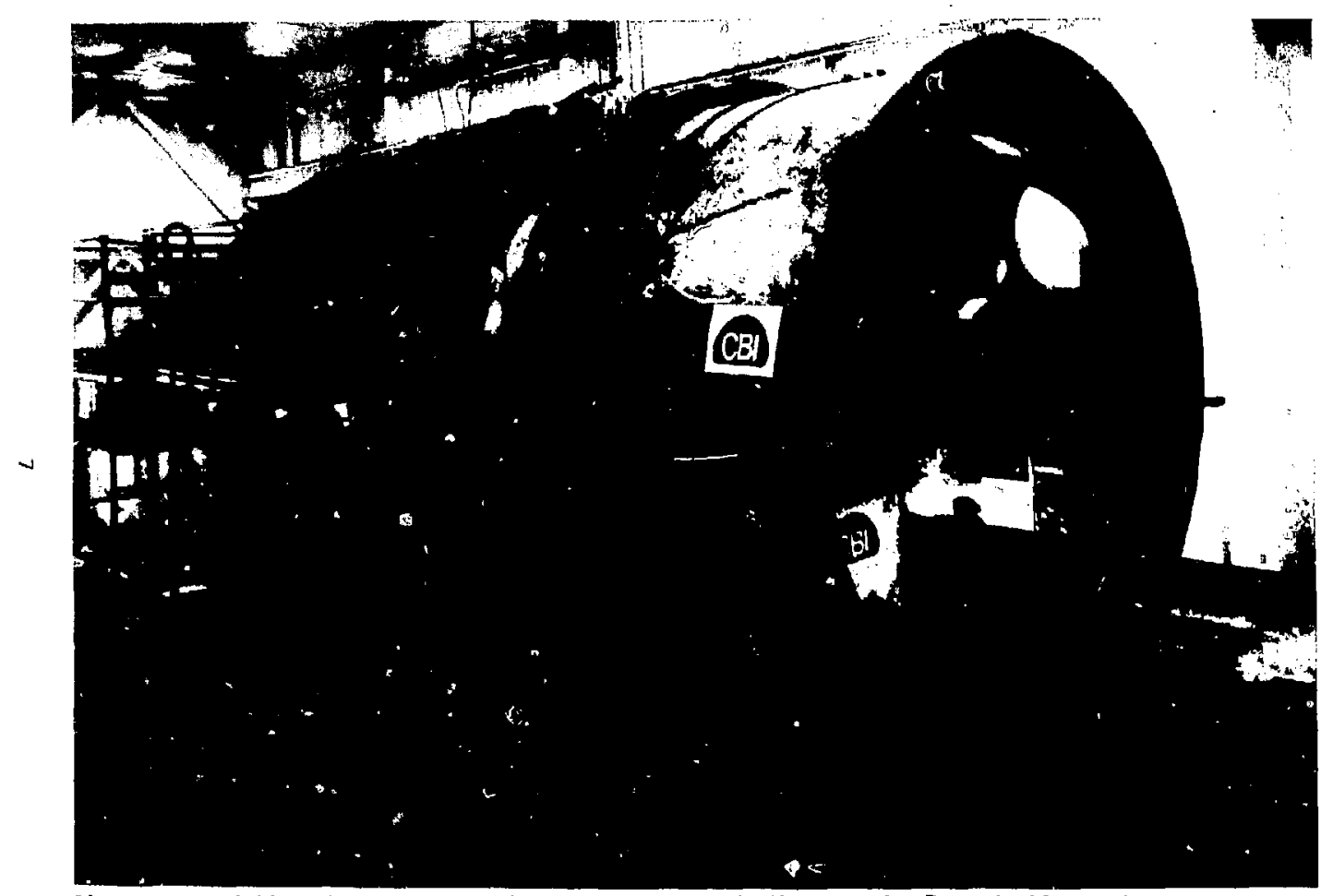

Fig. 5. Installation of the three-section process chamber in the Separator Demonstration Facility. 
evaluation process based on cost, capability, and schedule, the Chicago Bridge and Iron Company (CBI), Salt Lake City, UT, was selected to build the vessel. A contract for delivery by January 30, 1985 at a cost of $\$ 2,135,300$ was signed on January $9,1984$.

\section{FAERICATION}

Fabrication of the vessel was divided between two CBI shops to speed delivery. The 12-ft $(3.6-\mathrm{m})$-diam optics chambers were built in Birmingham, AL, with machining beling performed at noarby Cordoba. The remaining larger and harder-to-ship chambers were pabricated in Salt Lake City, UT. TO furtiner speed delsyery, much of the machining for the gas-scattering chambers was subcontracted to two outside shops: General Electric and Binghem-Willamette, both in Salt Lake city, UT. The two vacuum valves were vended to 1 B, Inc., Hayward, $\mathrm{CA}$. This company has built many large gate valves including those used on the Mars vessel. Throughout the contract WN has maintained daily communication with CBI and several visits have been made to Inspect on-going fabrication.

At present all major eletients of the tank have been fabricater, delivered to LLNL, and are in the process of being installed. 
INIERNAL OISTRIBUTION

R.E. Batzel

J.I. Davis

J.L. Emmet.t

A.C. Haussmann

$L-1$

$\mathrm{L}-466$

$\mathrm{L}-488$

L-28

R.D. Dewitt

$L-372$

T.W. Alger

G. Armantrout

E.R. Ault

R.C. Bell

H.L. Chen

A.R. Clobes

C.M. Cornell

M. Day

J.W. Dubrin

J.T. Early

R.G. Finucane

T.J. Gilmartin

L.A. Hackel

R.P. Hackel

M.P. Hacker

R.S. Hargrove

J.G. Harri

J.L. Held

R.E. Hendrickson

D.P. Hendry

F.J. Holconb
L-462

$L-468$

L-463

$\mathrm{L}-466$

L-468

$L-462$

L -468

$L-466$

$L-466$

L-466

L-462

L-467

L-470

$L-463$

L-470

L-467

L-470

L-470

$L-466$

L-466

L-466
J.Z. Holtz

L-459

M.A. Johnson

L-464

T. Kan

L-462

E.I. Moses

L-462

B.R. Myers

R.W. O'Neil

L-468

$L-462$

E.F. Oberst

$Y$. Oster

J.A. Palsner

R.W. Patterson

$L-440$

L-440

L-464

L -462

$L-443$

C.L. Pomernacki

$L-466$

R.S. Schechter

$L-470$

$L-464$

R.'W. Solarz

M.L. Spaeth

$L-467$

$L-459$

L. -445

F.M. Strange

$L-443$

J.R. Taylor

$1-441$

R.J. Vetterlein

L-468

J.M. Yatabe

L-466

T.J. Gilmartin Milestane File

$L-467$

J.I. Davis

L-466.

CLYA Files

(15)

TID

$L-658$

(15) 
Martin Marietta Energy Systems

A.S. Braden

D.F. Craig

J.P. Forester

C.E. Frye

R.L. Hoglund

c.C. Hopkins

T.J. Huxford

G.R. Jasny

K. Jarmolow

A.L. Lotts

D.W. McDonald

J.R. Merriman

G.E. Michaels

J.P. Moore

J.E. Owen

J.5. Rayside

J.E. Rushton

T.E. Smith

Martin Marietta

Energy Systems, Inc., K-25

Dak Ridge, TN

\section{Department of Energy}

R.E. Dierlan

N. Haberman

J.K. Hancock (Project File)

J.R. Longenecker

J.J. McClure

S.E. Peske

H.M. Polansky

US DOE

office of Uranium Enrichment

Washingtun, DC

(7)

R.T. Bredderman

US DOE

San Francisco Operations office Dakland, CA

R.T. Ooten

US DOE

Dak Ridge Operations office

Dak Ridge, TN

US DOE

Technical Information Center

Dak Ridge, TN

(27) 